\title{
Low incidence of new biochemical and clinical hypogonadism following hypofractionated stereotactic body radiation therapy (SBRT) monotherapy for low- to intermediate-risk prostate cancer
}

Eric K Oermann', Simeng Suy ${ }^{1}$, Heather N Hanscom¹, Joy S Kim¹, Sue Lei ${ }^{1}$, Xia Yu', Guowei Zhang ${ }^{1}$, Brook Ennis ${ }^{1}$, JoyAnn P Rohan ${ }^{4}$, Nathaniel Piel', Benjamin A Sherer², Devin Borum', Viola J Chen', Gerald P Batipps²,

Nicholas L Constantinople ${ }^{2}$, Stephen W Dejter ${ }^{2}$, Gaurav Bandi², John Pahira², Kevin G McGeagh², Lucile Adams-Campbell ${ }^{4}$, Reena Jha ${ }^{3}$, Nancy A Dawson ${ }^{4}$, Brian T Collins ${ }^{1}$, Anatoly Dritschilo', John H Lynch $^{2}$ and Sean P Collins ${ }^{1 *}$

\begin{abstract}
Background: The CyberKnife is an appealing delivery system for hypofractionated stereotactic body radiation therapy (SBRT) because of its ability to deliver highly conformal radiation therapy to moving targets. This conformity is achieved via 100s of non-coplanar radiation beams, which could potentially increase transitory testicular irradiation and result in post-therapy hypogonadism. We report on our early experience with CyberKnife SBRT for low- to intermediate-risk prostate cancer patients and assess the rate of inducing biochemical and clinical hypogonadism.
\end{abstract}

Methods: Twenty-six patients were treated with hypofractionated SBRT to a dose of 36.25 Gy in 5 fractions. All patients had histologically confirmed low- to intermediate-risk prostate adenocarcinoma (clinical stage $\leq \mathrm{T} 2 \mathrm{~b}$, Gleason score $\leq 7$, PSA $\leq 20 \mathrm{ng} / \mathrm{ml}$ ). PSA and total testosterone levels were obtained pre-treatment, 1 month posttreatment and every 3 months thereafter, for 1 year. Biochemical hypogonadism was defined as a total serum testosterone level below $8 \mathrm{nmol} / \mathrm{L}$. Urinary and gastrointestinal toxicity was assessed using Common Toxicity Criteria v3; quality of life was assessed using the American Urological Association Symptom Score, Sexual Health Inventory for Men and Expanded Prostate Cancer Index Composite questionnaires.

Results: All 26 patients completed the treatment with a median 15 months (range, 13-19 months) follow-up. Median pre-treatment PSA was $5.75 \mathrm{ng} / \mathrm{ml}$ (range, $2.3-10.3 \mathrm{ng} / \mathrm{ml}$ ), and a decrease to a median of $0.7 \mathrm{ng} / \mathrm{ml}$ (range, 0.2-1.8 $\mathrm{ng} / \mathrm{ml}$ ) was observed by one year post-treatment. The median pre-treatment total serum testosterone level was $13.81 \mathrm{nmol} / \mathrm{L}$ (range, $5.55-39.87 \mathrm{nmol} / \mathrm{L}$ ). Post-treatment testosterone levels slowly decreased with the median value at one year follow-up of $10.53 \mathrm{nmol} / \mathrm{L}$, significantly lower than the pre-treatment value $(p<0.013)$. The median absolute fall was $3.28 \mathrm{nmol} / \mathrm{L}$ and the median percent fall was $23.75 \%$. There was no increase in biochemical hypogonadism at one year post-treatment. Average EPIC sexual and hormonal scores were not significantly changed by one year post-treatment.

\footnotetext{
* Correspondence: spc9@gunet.georgetown.edu

'Department of Radiation Medicine, Georgetown University Hospital,

Washington, D.C., USA

Full list of author information is available at the end of the article
} 


\section{Background}

Recent analyses of clinical data suggest that large radiation fraction sizes are radiobiologically favorable compared to smaller fraction sizes in prostate cancer radiotherapy [1]. The CyberKnife (Accuray, Inc., Sunnyvale, $\mathrm{CA}$ ) is an FDA-approved radiosurgical device that is ideal for accurately delivering hypofractionated stereotactic body radiation therapy (SBRT) [2]. Treatment is delivered by a linear accelerator mounted on a flexible robotic arm. A few hundred treatment beams are selected from a repertoire of greater than one thousand possible beam directions using inverse treatment planning. These beams are delivered in a non-isocentric, non-coplanar manner via circular collimators of varying sizes. Access to a large number of potential beam trajectories allows delivery of a highly conformal dose with steep dose gradients $[3,4]$. Unlike standard radiation therapy delivery systems, the CyberKnife system incorporates a dynamic tracking system consisting of an orthogonal pair of diagnostic-quality $\mathrm{x}$-ray imaging devices and software that can locate fiducials implanted within the prostate [5]. This provides updated position information in six dimensions (three translations combined with roll, pitch and yaw rotations) [6] to the robot, which adjusts the targeting of the therapeutic beam during treatment to correct for intra-fraction motion. These features allow for a reduction in the planning target volume (PTV) and potentially the dose to surrounding critical organs. These technical improvements should allow for dose escalation within the prostate while maintaining normal tissue tolerance.

The early efficacy and safety of CyberKnife hypofractionated dose-escalated SBRT have been documented for localized treatment of prostate cancer [7-9]. Stanford's phase II protocol delivered 36.25 Gy in 5 fractions of 7.25 Gy. This dose and fractionation were selected for radiobiologic dose escalation while keeping a constant predicted normal tissue late effect. In King et al.'s report on 41 "low-risk" patients, at a median of 33 months after treatment, the mean PSA was $0.44 \mathrm{ng} / \mathrm{ml}$ [7], suggesting a high rate of long-term control [10]. No patient experienced grade 4 toxicity, and only two patients experienced grade 3 late urinary morbidity. Similar results with similar regimens have been reported by others $[8,9]$.

Due to anatomic proximity, the testes are at risk for exposure to scattered radiation during prostate treatment. It has been suggested that the non-coplanar nature of CyberKnife SBRT may increase the risk of testicular irradiation during treatment [11]. The resulting decline in testosterone levels $[12,13]$ could be responsible for the low PSA nadirs [14] obtained with CyberKnife SBRT. If so, the post-treatment PSA response may not accurately reflect the likelihood of long-term tumor control with such treatment [10]. Equally important, the resulting endocrine changes may contribute to postradiation hypogonadism with subsequent depression, cognitive decline, decreased libido and impotence [15]. Knowledge of the relative risks of hypogonadism due to available treatment options for prostate cancer could affect patients' treatment decisions. In this paper, we report on the use of CyberKnife SBRT as monotherapy for the treatment of 26 prostate cancer patients and show that the risk of new biochemical and clinical hypogonadism is low within the first year after treatment.

\section{Methods}

\section{Patient Selection}

Patients eligible for inclusion in this study had histologically-confirmed low- to intermediate-risk adenocarcinoma of the prostate (clinical stage $\leq \mathrm{T} 2 \mathrm{~b}$, Gleason score $\leq 7, \mathrm{PSA} \leq 20 \mathrm{ng} / \mathrm{ml}$ ). Exclusion criteria included androgen deprivation therapy, clinically involved lymph nodes on imaging, distant metastases on bone scan, prior pelvic radiotherapy or prior radical prostate surgery. Institutional IRB approval was obtained for this retrospective review.

\section{SBRT Treatment Planning and Delivery}

Four gold fiducials were placed into the prostate prior to treatment planning: two at the apex and two at the base. To allow for fiducial stabilization, planning imaging was performed at least 7 days after fiducial placement. Patients underwent 1.5 T MR imaging followed shortly thereafter by a thin-cut $(1.25 \mathrm{~mm})$ CT scan. Both scans were performed with an empty bladder. Patients were advised to adhere to a low-fiber diet, starting at least five days prior to all treatment planning imaging and treatment delivery. They were restricted to nothing by mouth (NPO) the night before, and an enema was administered 1-2 hours prior to imaging and treatment.

Fused CT and MR images were used for treatment planning (Figure 1). The gross target volume (GTV) was the prostate. The clinical target volume (CTV) included the prostate and the proximal seminal vesicles to the point where the left and right seminal vesicles separate. 


$$
\text { A. }
$$

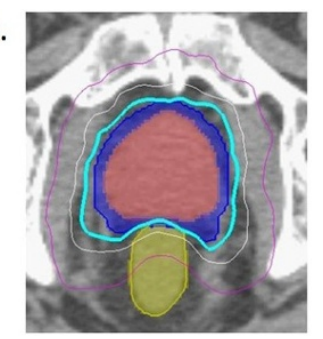

B.

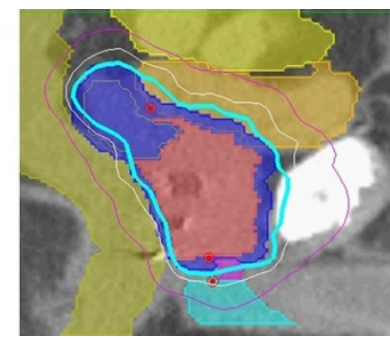

Figure 1 Treatment planning axial (A) and sagittal (B) computed tomography images demonstrating the GTV (red), CTV and PTV expansion (dark blue), bladder (orange), rectum (green), bowel (yellow), membranous urethra (pink) and penile bulb (light blue). Isodose lines shown as follows: Blue 79\% (prescription), white $70 \%$ and purple $50 \%$.

The PTV equaled the CTV expanded $3 \mathrm{~mm}$ posteriorly and $5 \mathrm{~mm}$ in all other dimensions. The prescription dose was 36.25 Gy to the PTV delivered in five fractions of 7.25 Gy over two weeks. The volume of the PTV receiving 36.25 Gy was at least $95 \%$. The prescription isodose line was limited to $\geq 75 \%$, which limited the maximum prostatic urethra dose to $133 \%$ of the prescription dose. The rectum, bladder, testes, penile bulb and membranous urethra were contoured structures and evaluated with dose-volume histogram analysis during treatment planning using Multiplan (Accuray Inc., Sunnyvale, CA) inverse treatment planning. Rectal volume receiving 36 Gy was limited to $<1 \mathrm{cc}$. The rectal dosevolume histogram (DVH) goals were $<50 \%$ rectal volume receiving $50 \%$ of the prescribed dose, $<20 \%$ receiving $80 \%$ of the dose, $<10 \%$ receiving $90 \%$ of the dose, and $<5 \%$ receiving $100 \%$ of the dose [7]. The empty bladder volume receiving 37 Gy was limited to < $10 \mathrm{cc}$ [8]. Care was taken to avoid treatment beams that directly traversed the testes, and the scatter dose was kept to a minimum. Image-guidance was employed to minimize the required PTV treatment margins. Using computed tomography planning, target volume locations were related to the gold fiducial markers. Position verification was validated several times per minute during treatment using paired, orthogonal, and $\mathrm{x}$-ray images.

\section{Follow-up}

PSA and total testosterone levels were obtained before treatment, one month after the completion of radiation, and during routine follow-up visits every 3 months for the first year. Samples were obtained in the morning and early afternoon to limit the effects of circadian variation [16]. Biochemical hypogonadism was defined as total serum testosterone level below $8 \mathrm{nmol} / \mathrm{L}$ [17]. Toxicity was assessed pre-treatment and at 1, 3, 6, 9 and 12 months post-treatment using the National Cancer Institute (NCI) Common Toxicity Criteria (CTC) version 3.0 [18] and the American Urological Association (AUA) symptom score (also known as International Prostate Symptom Score) [19]. Quality of life (QoL) was assessed pre-treatment and at follow-up visits using the Short Form-12 Health Survey (SF-12), the Expanded Prostate Cancer Index Composite (EPIC) [20] and the Sexual Health Inventory for Men (SHIM) [21].

\section{Statistical Analysis}

Skewed continuous variables, e.g., testosterone and PSA, were described as the sample median and range. Categorical variables were described as frequency and percentage. Obtaining PSA, total testosterone, and quality of life measurements sequentially in each patient constitutes a natural control for potentially wide baseline variation across patients. Therefore responses to radiotherapy were assessed using non-parametric pairwise Wilcoxon rank-sum testing [22].

\section{Results}

From January 2009 to June 2009, 26 prostate cancer patients were treated per our institutional protocol. Their median age was 69 years (range, 48-79 years). Similar numbers of Caucasians and African-Americans were enrolled reflecting the distribution of our patient population. Fourteen patients were low-risk, and 12 patients were intermediate-risk per the D'Amico Risk Classification [23]. Table 1 provides detailed patient characteristics.

At a median follow-up of 15 months (range, 13-19 months), the initial PSA response has been favorable, with decreased PSA levels in all patients. The median pre-treatment PSA was $5.75 \mathrm{ng} / \mathrm{ml}$ (range, $2.3-10.3 \mathrm{ng} /$ $\mathrm{ml}$ ); it decreased to a median of $0.7 \mathrm{ng} / \mathrm{ml}$ (range, 0.2 $1.8 \mathrm{ng} / \mathrm{ml}$ ) by one year post-treatment (Figure $2 \mathrm{~A}$ ), suggesting a high rate of long term disease control using this treatment regimen [24].

Consistent with our elderly patient population, pretreatment total serum testosterone levels were low, ranging from $5.55 \mathrm{nmol} / \mathrm{L}$ to $39.87 \mathrm{nmol} / \mathrm{L}$ with a median value of $13.81 \mathrm{nmol} / \mathrm{L}[25]$. The median testicular scatter dose was 2.1 Gy (range, 1.1-5.8 Gy). Post-treatment total serum testosterone levels fell in 18 patients $(69 \%)$ and increased in 8 patients (31\%). At one year the median serum testosterone value of $10.53 \mathrm{nmol} / \mathrm{L}$ (range, $5.79-22.38 \mathrm{nmol} / \mathrm{L}$ ) was significantly lower than the pre-treatment value $(p<0.013)$ (Figure $2 \mathrm{~B})$. The median absolute fall was small $(3.28 \mathrm{nmol} / \mathrm{L})$ and the median percent fall was $23.75 \%$. Pre- and post-treatment median total testosterone levels are shown in Figure 2B. In contrast to the total serum testosterone levels, the PSA to testosterone ratio decreased in all the patients, suggesting that the PSA decrease was not due solely to the drop in testosterone (Figure 2C). Based on the 
Table 1 Pre-treatment patient characteristics

\begin{tabular}{|c|c|c|c|c|c|c|c|c|c|}
\hline$\#$ & Age & Race & PSA (ng/mL) & T Stage & Gleason Score & Risk Group & Prostate Volume (cc) & $A \cup A$ & SHIM \\
\hline 1 & 60 & Cau & 4.7 & $1 \mathrm{c}$ & $3+3$ & Low & 53 & 3 & 20 \\
\hline 2 & 69 & Cau & 6.8 & $1 \mathrm{c}$ & $3+4$ & Intermediate & 46 & 3 & 14 \\
\hline 3 & 69 & Cau & 6.1 & $1 c$ & $3+3$ & Low & 29 & 9 & 1 \\
\hline 4 & 60 & Cau & 4.5 & $1 c$ & $3+3$ & Low & 21 & 3 & 18 \\
\hline 5 & 71 & $A A$ & 4.0 & $1 c$ & $2+3$ & Low & 31 & 16 & 19 \\
\hline 6 & 72 & Cau & 5.6 & $1 \mathrm{c}$ & $3+3$ & Low & 41 & 4 & 1 \\
\hline 7 & 56 & AA & 5.7 & $1 c$ & $3+3$ & Low & 43 & 9 & 16 \\
\hline 8 & 70 & Cau & 4.9 & $1 c$ & $3+3$ & Low & 23 & 4 & 21 \\
\hline 9 & 74 & Cau & 4.9 & $1 \mathrm{c}$ & $3+3$ & Low & 45 & 10 & 15 \\
\hline 10 & 78 & Cau & 8.1 & $2 b$ & $3+3$ & Intermediate & 33 & 1 & 3 \\
\hline 11 & 71 & Cau & 4.9 & $1 c$ & $3+3$ & Low & 33 & 5 & 20 \\
\hline 12 & 58 & $\mathrm{AA}$ & 7.9 & $1 \mathrm{c}$ & $3+4$ & Intermediate & 37 & 12 & 21 \\
\hline 13 & 66 & Cau & 10.3 & $1 c$ & $3+3$ & Intermediate & 34 & 14 & 25 \\
\hline 14 & 74 & AA & 6.3 & $1 \mathrm{c}$ & $4+3$ & Intermediate & 55 & 9 & 4 \\
\hline 15 & 70 & Cau & 6.8 & $1 c$ & $3+3$ & Low & 30 & 21 & 20 \\
\hline 16 & 62 & Cau & 4.0 & $1 \mathrm{c}$ & $3+4$ & Intermediate & 30 & 1 & 25 \\
\hline 17 & 79 & Cau & 2.3 & $2 b$ & $3+4$ & Intermediate & 52 & 5 & 3 \\
\hline 18 & 48 & AA & 6.8 & $1 c$ & $3+3$ & Low & 18 & 8 & 24 \\
\hline 19 & 73 & Cau & 6.9 & $1 c$ & $3+4$ & Intermediate & 40 & 3 & 4 \\
\hline 20 & 62 & Cau & 5.6 & $1 \mathrm{c}$ & $3+3$ & Low & 25 & 6 & 23 \\
\hline 21 & 63 & AA & 6.2 & $1 \mathrm{c}$ & $3+4$ & Intermediate & 42 & 4 & 15 \\
\hline 22 & 69 & AA & 5.8 & $1 c$ & $3+4$ & Intermediate & 42 & 6 & 18 \\
\hline 23 & 71 & AA & 5.9 & $1 \mathrm{c}$ & $3+3$ & Low & 34 & 2 & 24 \\
\hline 24 & 65 & Cau & 7.4 & $1 \mathrm{c}$ & $4+3$ & Intermediate & 33 & 7 & 24 \\
\hline 25 & 78 & AA & 4.2 & $2 b$ & $4+3$ & Intermediate & 37 & 10 & 1 \\
\hline 26 & 67 & Cau & 4 & $2 a$ & $3+3$ & Low & 49 & 5 & 20 \\
\hline
\end{tabular}

International Society for the Study of the Aging Male (ISSAM) definition $(<8 \mathrm{nmol} / \mathrm{L})$ [18], the pre-treatment and 1-year biochemical hypogonadism rates were identical (Figure 3).

Toxicity has been minimal with no Grade 3 or higher gastrointestinal (GI) or gastrourinary (GU) toxicities (Table 2). Grade 1 and 2 acute toxicities included urinary symptoms requiring alpha blockers and bowel frequency/spasms requiring antidiarrheals. At one year post-treatment, the patients' perceptions of their physical (Figure 4A) and mental health (Figure 4B) were unchanged (Table 3). At one month post-treatment the mean AUA toxicity increased to 10.8 from a baseline of $6.8(p=0.0001)$, and the mean EPIC urinary score decreased to 82.7 from a baseline $90.5(p=0.0001)$, see Figures $5 \mathrm{~A}$ and $5 \mathrm{~B}$ and Table 3 . Both mean AUA and EPIC urinary scores returned to baseline by one year after treatment. At one month post-treatment, the mean EPIC bowel score declined to 91.7 from a baseline of $95.7(p=0.042)$ (see Figure $5 \mathrm{C}$ and Table 3 ) and returned to baseline by one year after treatment.
Sexual dysfunction is a major criterion for the clinical diagnosis of hypogonadism [26]. At one year post-treatment, the mean SHIM decreased to 14.3 from a baseline of 17.2, and the mean EPIC sexual scores decreased to 60.1 from a baseline of 66.7 (Figures 6A and 6B, Table $3)$. However, these changes were small and not statistically ( $p=0.126$ and $p=0.341$, respectively) or clinically significant [27]. At one month post-treatment, the mean EPIC hormone score declined to 90.9 from a baseline of $94.2(p=0.039)$; it returned to baseline by one year post-treatment (Figure 6C and Table 3).

\section{Discussion}

Pelvic irradiation causes a dose-dependent reduction in serum testosterone levels that increases with larger field sizes and higher testicular doses [28]. For conventional pelvic radiation therapy, the drop is approximately 10 $30 \%$; this reaches a nadir, on average, several months post-treatment and can persist for years thereafter [28-33]. In addition to precipitating clinical hypogonadism, with its adverse effects [15], this testosterone 


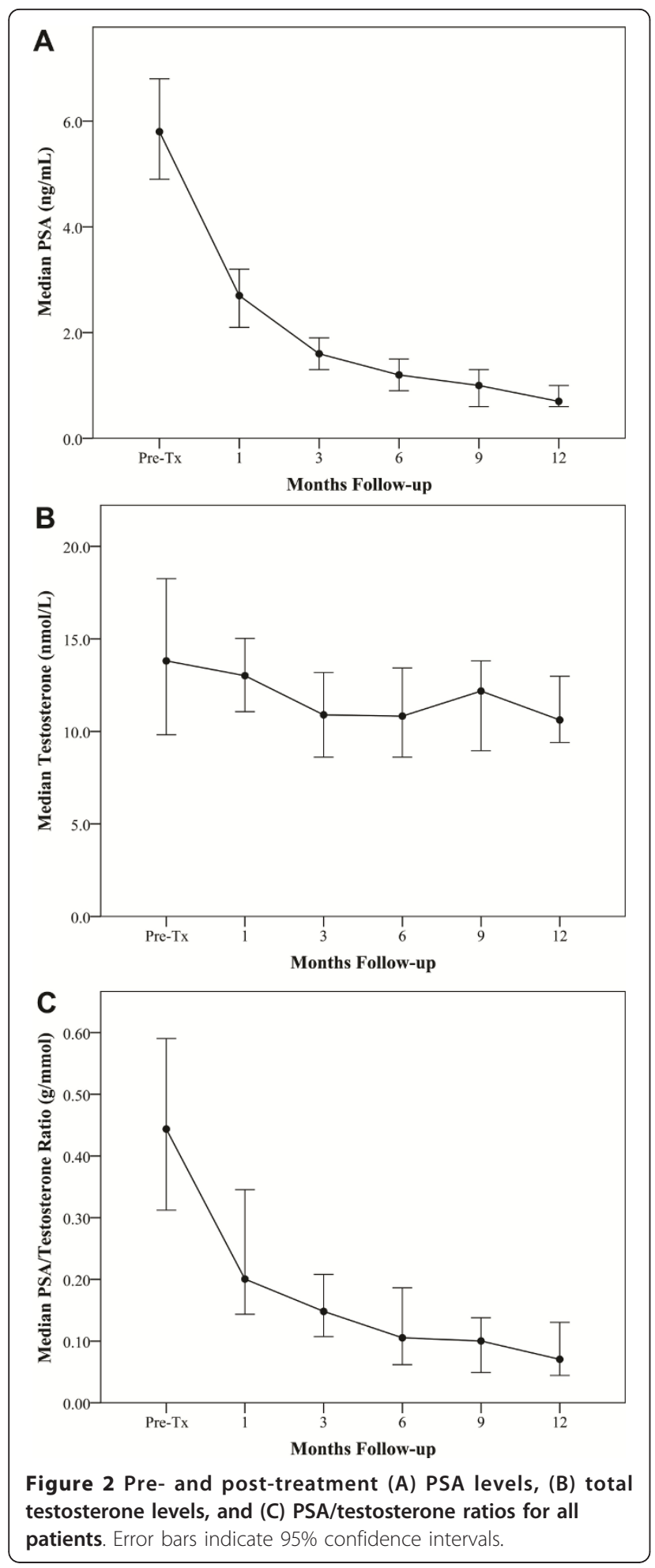

decline may undermine the utility of PSA as a tumor response marker [10]. Radiation dose escalation, hypofractionation, and the increased total body radiation with multi-field treatments [34] and image guidance [35] could enhance this testosterone decline. Thus, this

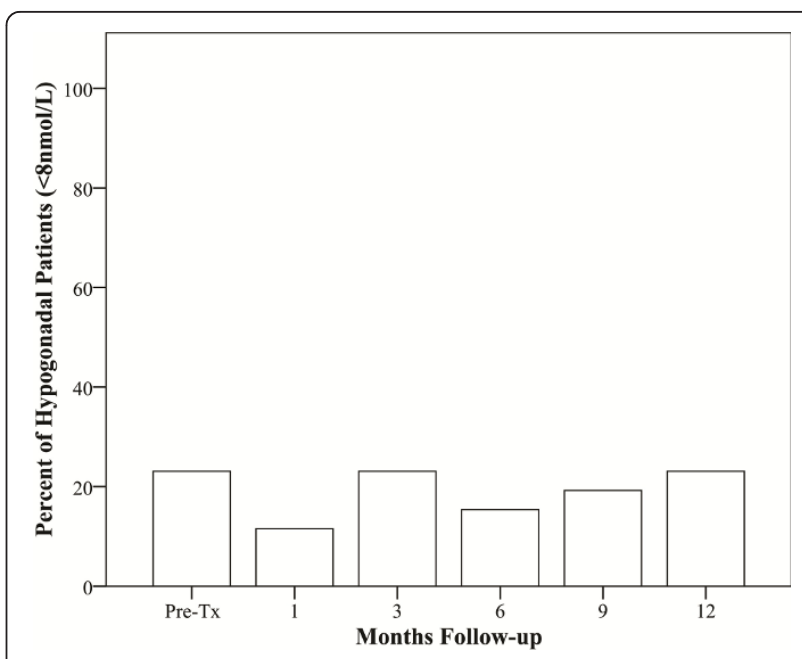

Figure 3 Comparison of pre-treatment biochemical hypogonadism rates to those at up to 1 year following treatment

study was aimed to assess the risk of biochemical and clinical hypogonadism following CyberKnife SBRT monotherapy for clinically localized prostate cancer.

In our study, we observed a small decline $(23.75 \%)$ in total testosterone levels after SBRT treatment consistent with that reported by others [36] and similar to that seen with conventional prostate radiation therapy [30]. This decline in testosterone was unlikely responsible for a promising 12-month PSA nadir as variations in serum testosterone do not greatly affect PSA levels in eugonadal men $[37,38]$. It remains to be determined whether testosterone decreases are temporary or permanent as these levels can take years to normalize [28]. Future studies will determine if testosterone levels fully recover to age-appropriate levels in our patient population.

The cause of this testosterone decline is unknown. Leydig cell dysfunction due to testicular scatter irradiation (mean dose of 2-4 Gy) in older men has been proposed as the major causative factor [12,29,31-33]. However, normal age-related testosterone decline [25] and treatment related stress [39] may also contribute. To determine if emotional and physiological stress could be responsible for our small decline in total testosterone, we examined acute toxicity and quality of life indicators. Acute Grade $2 \mathrm{GU}$ and GI toxicities were observed in $27 \%$ and $0 \%$ of patients, respectively (Table 2 ). There were no Grade 3 or higher acute toxicities. These results appear comparable to other published external beam radiation therapy series $[19,40,41]$. In the opinion of the authors, it is unlikely that these minimal toxicities were responsible for the observed decline in serum testosterone. Consistent with findings of others, the small decline in total testosterone had minimal effects on quality of life [42]. Our AUA, SHIM and 
Table 2 Summary of CTC graded acute gastrointestinal (GI) and genitourinary (GU) toxicities

\begin{tabular}{|c|c|c|c|c|c|c|c|c|c|}
\hline \multirow{2}{*}{$\begin{array}{l}\text { Gastrointestinal } \\
\text { Toxicity }\end{array}$} & \multirow[b]{2}{*}{ Grade } & \multicolumn{2}{|c|}{ Pre-Tx } & \multicolumn{2}{|c|}{1 Month } & \multicolumn{2}{|c|}{3 Month } & \multicolumn{2}{|c|}{6 Month } \\
\hline & & $\mathrm{N}$ & $\%$ & $\mathrm{~N}$ & $\%$ & $\mathrm{~N}$ & $\%$ & $\mathrm{~N}$ & $\%$ \\
\hline \multirow[t]{3}{*}{ Diarrhea } & 0 & 21 & (81) & 19 & (73) & 21 & (81) & 20 & (77) \\
\hline & 1 & 5 & (19) & 7 & (27) & 5 & (19) & 6 & (23) \\
\hline & 2 & 0 & (0) & 0 & (0) & 0 & (0) & 0 & (0) \\
\hline \multirow[t]{3}{*}{ Proctitis } & 0 & 26 & (100) & 22 & (85) & 23 & (88) & 24 & (92) \\
\hline & 1 & 0 & $(0)$ & 4 & (15) & 3 & (12) & 2 & (8) \\
\hline & 2 & 0 & (0) & 0 & $(0)$ & 0 & $(0)$ & 0 & (0) \\
\hline Rectal & 0 & 25 & (96) & 25 & (96) & 25 & (96) & 25 & (96) \\
\hline \multirow[t]{2}{*}{ Bleeding } & 1 & 1 & (4) & 1 & (4) & 1 & (4) & 1 & (4) \\
\hline & 2 & 0 & (0) & 0 & (0) & 0 & (0) & 0 & (0) \\
\hline \multirow[t]{4}{*}{ Highest Gl } & 0 & 20 & (77) & 16 & (62) & 19 & (73) & 19 & (73) \\
\hline & 1 & 6 & (23) & 10 & (38) & 7 & (27) & 7 & (27) \\
\hline & 2 & 0 & (0) & 0 & $(0)$ & 0 & $(0)$ & 0 & $(0)$ \\
\hline & & \multicolumn{2}{|c|}{ Pre-Tx } & \multicolumn{2}{|c|}{1 Month } & \multicolumn{2}{|c|}{3 Month } & \multicolumn{2}{|c|}{6 Month } \\
\hline Toxicity & Grade & $\mathrm{N}$ & $\%$ & $\mathrm{~N}$ & $\%$ & $\mathrm{~N}$ & $\%$ & $\mathrm{~N}$ & $\%$ \\
\hline \multirow[t]{3}{*}{ Hematuria } & 0 & 26 & (100) & 26 & (100) & 26 & (100) & 26 & (100) \\
\hline & 1 & 0 & (0) & 0 & $(0)$ & 0 & (0) & 0 & (0) \\
\hline & 2 & 0 & (0) & 0 & (0) & 0 & (0) & 0 & (0) \\
\hline \multirow[t]{3}{*}{ Dysuria } & 0 & 22 & (85) & 17 & (65) & 25 & (96) & 25 & (96) \\
\hline & 1 & 4 & (15) & 9 & (35) & 1 & $(4)$ & 1 & (4) \\
\hline & 2 & 0 & $(0)$ & 0 & $(0)$ & 0 & (0) & 0 & $(0)$ \\
\hline \multirow[t]{3}{*}{ Incontinence } & 0 & 25 & (96) & 18 & (69) & 19 & (73) & 21 & (81) \\
\hline & 1 & 1 & (4) & 7 & (27) & 7 & (27) & 5 & (19) \\
\hline & 2 & 0 & (0) & 1 & (4) & 0 & (0) & 0 & (0) \\
\hline Urinary & 0 & 26 & (100) & 23 & (88) & 23 & (88) & 23 & (88) \\
\hline \multirow[t]{2}{*}{ Freq/Urg } & 1 & 0 & (0) & 3 & (12) & 3 & (12) & 3 & (12) \\
\hline & 2 & 0 & (0) & 0 & $(0)$ & 0 & $(0)$ & 0 & $(0)$ \\
\hline \multirow[t]{3}{*}{ Retention } & 0 & 14 & (54) & 5 & (19) & 9 & (35) & 8 & (31) \\
\hline & 1 & 12 & $(46)$ & 14 & $(54)$ & 10 & (38) & 12 & (46) \\
\hline & 2 & 0 & $(0)$ & 7 & (27) & 7 & (27) & 6 & (23) \\
\hline \multirow[t]{4}{*}{ Highest GU } & 0 & 13 & (50) & 5 & (19) & 7 & (27) & 8 & (31) \\
\hline & 1 & 13 & (50) & 14 & (54) & 12 & (46) & 12 & (46) \\
\hline & 2 & 0 & $(0)$ & 7 & (27) & 7 & (27) & 6 & (23) \\
\hline & 2 & 0 & (0) & 0 & (0) & 0 & (0) & 0 & (0) \\
\hline
\end{tabular}
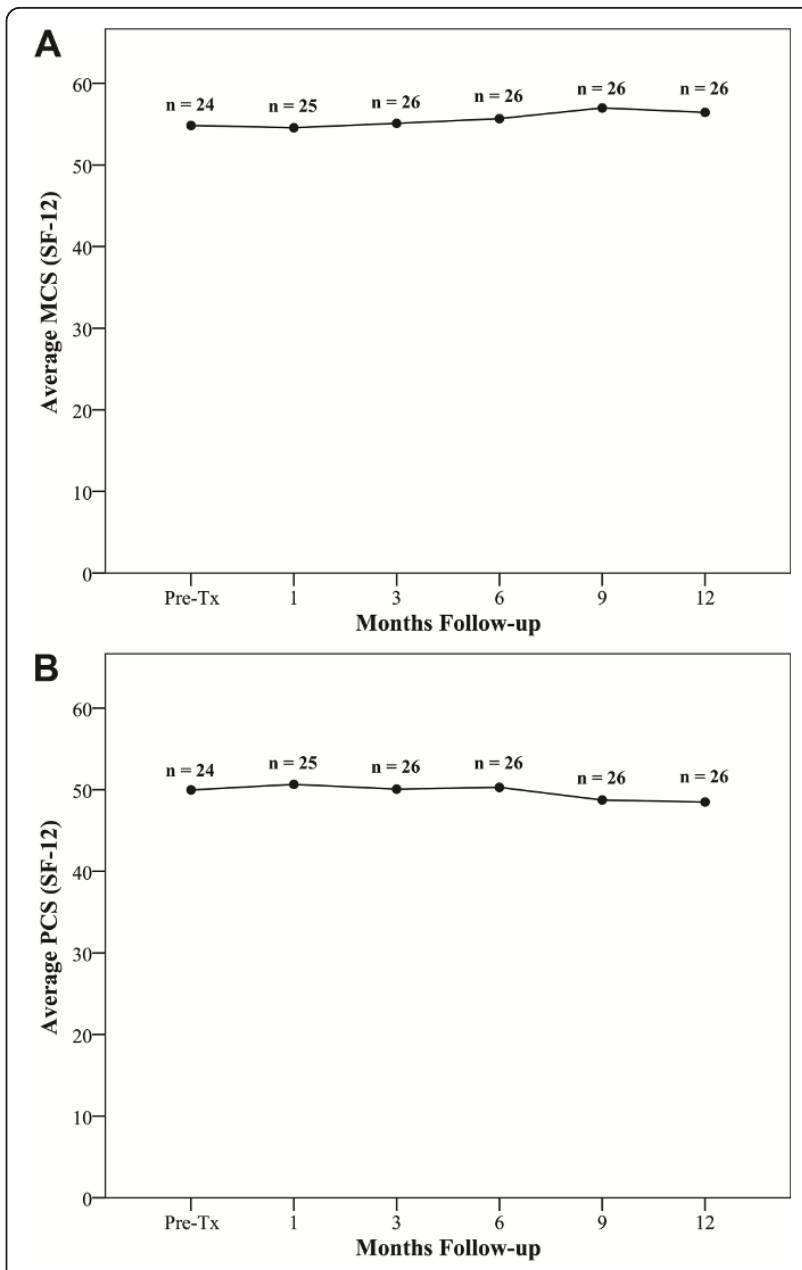

Figure 4 Short Form-12 (SF-12) Health Survey quality of life: (A) SF-12 physical component score (PCS) and (B) SF-12 mental component score (MCS). The graphs show unadjusted changes in average scores over time. The scores range from 0 - 100 with higher values representing improved health status. Numbers above each time point indicate the number of observations contributing to the average.

Table 3 Overview of patient quality of life (QoL)

\begin{tabular}{|c|c|c|c|c|c|c|}
\hline & Pre-Treatment & 1 Month & 3 Month & 6 Month & 9 Month & 12 Month \\
\hline SF-12 PCS & $50(35.2-58.9)$ & $50.9(31.4-61.4)$ & $50.5(31.4-61.2)$ & $50.6(25.7-56.7)$ & $49(27.1-57.2)$ & $49(27.6-59.8)$ \\
\hline SF-12 MCS & $54.8(37.2-61.3)$ & $54.4(41.2-61)$ & $55.2(37.3-63.2)$ & $55.7(34.5-61.5)$ & $57(47.1-64.7)$ & $56.5(38.5-62.6)$ \\
\hline AUA & $6.8(1-21)$ & $10.8(3-20)$ & $8.1(1-21)$ & $7.7(1-23)$ & $7.5(2-26)$ & $7.4(0-22)$ \\
\hline SHIM & $17.2(3-25)$ & $16(1-25)$ & $15(1-25)$ & $15.2(1-25)$ & $15.6(1-25)$ & $14.3(1-25)$ \\
\hline EPIC Urinary & $90.5(63-100)$ & $82.7(61.1-100)$ & $87.7(53.7-100)$ & $88.5(65.8-100)$ & $88.1(68.6-100)$ & $89(60.2-100)$ \\
\hline EPIC Bowel & $95.7(66.7-100)$ & $91.7(62.5-100)$ & $92.6(66.7-100)$ & $94.1(70.8-100)$ & $94.1(62.5-100)$ & $94.8(75-100)$ \\
\hline EPIC Sexual & $66.7(27.8-95.8)$ & $66.4(20.8-100)$ & $59.9(0-100)$ & $59.8(0-100)$ & $60(16.7-100)$ & $60.1(13.8-100)$ \\
\hline EPIC Hormonal & $94.2(75-100)$ & $90.9(70-100)$ & $90.8(60-100)$ & $92.3(60-100)$ & $93.6(60-100)$ & $92.1(60-100)$ \\
\hline
\end{tabular}

The table shows unadjusted changes in mean toxicity and QOL scores over time. SF-12 scores range from 0 - 100 with higher values representing improved health status. AUA scores range from 0 - 35 with higher values representing worsening urinary symptoms. SHIM scores range from 0 - 25 with lower values representing worsening sexual function. EPIC scores range from 0 - 100 with higher values representing a more favorable health-related QOL. Bolded items signify a statistically significant change in reported QoL from baseline measured by Wilcoxon rank sum test at 0.05 significance level. 

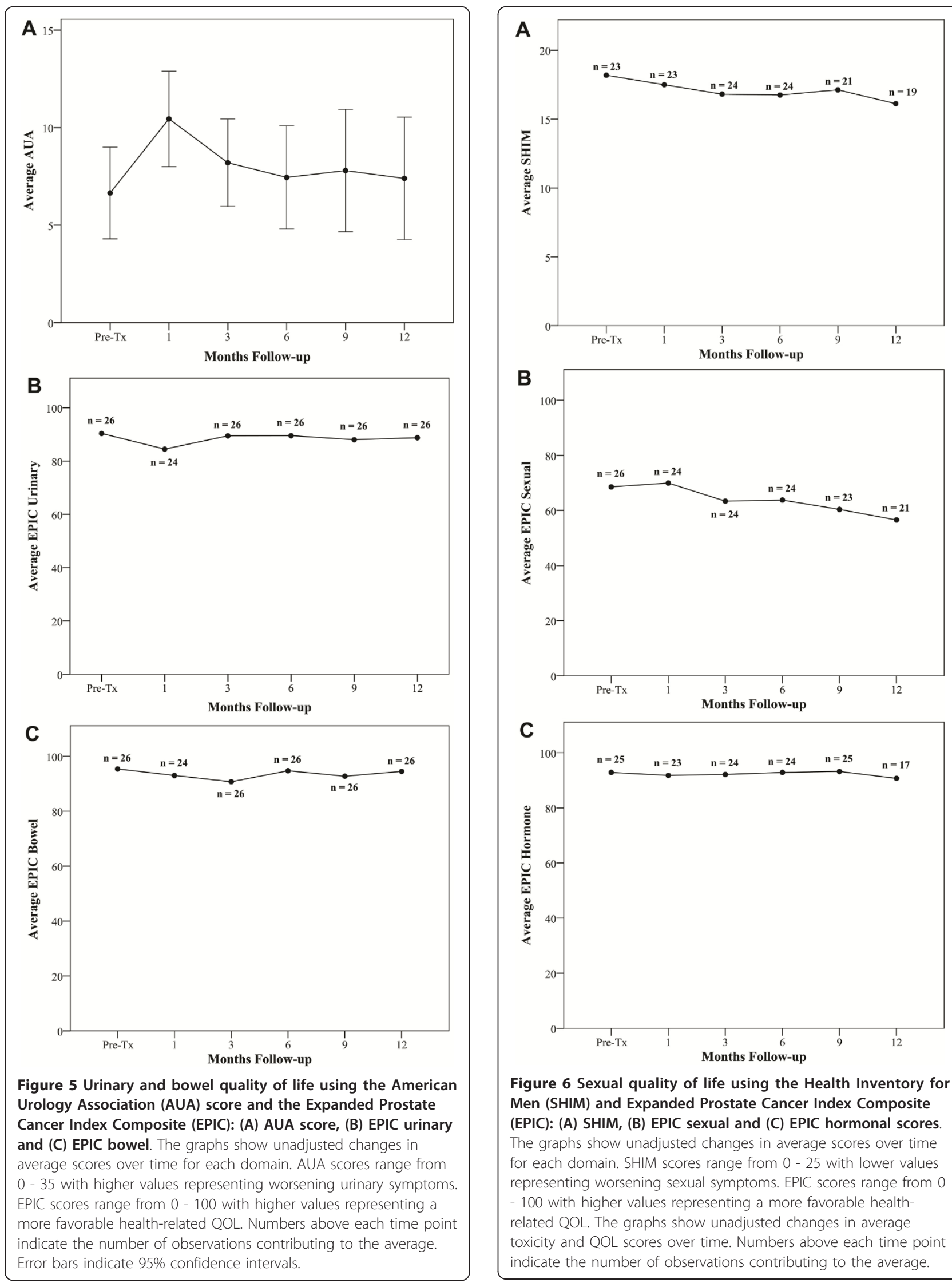

Figure 6 Sexual quality of life using the Health Inventory for Men (SHIM) and Expanded Prostate Cancer Index Composite (EPIC): (A) SHIM, (B) EPIC sexual and (C) EPIC hormonal scores. The graphs show unadjusted changes in average scores over time for each domain. SHIM scores range from 0 - 25 with lower values representing worsening sexual symptoms. EPIC scores range from 0 - 100 with higher values representing a more favorable healthrelated QOL. The graphs show unadjusted changes in average toxicity and QOL scores over time. Numbers above each time point indicate the number of observations contributing to the average. 
EPIC scores returned to baseline by one year after treatment (Table 3 and Figures 5 and 6). This is not unexpected as a total testosterone of $8 \mathrm{nmol} / \mathrm{L}$ is likely adequate for normal physiologic and sexual functioning [18]. Whatever the cause, the small decline in total testosterone does not appear to be clinically significant as it did not adversely affect the utility of the PSA as a measure of tumor response or induced clinical hypogonadism.

\section{Conclusions}

Hypofractionated SBRT is a promising new treatment option for men with low- and intermediate-risk prostate cancer. Early results suggest encouraging biochemical response with low toxicity and a low rate of new biochemical and clinical hypogonadism one year after treatment Investigation of more patients with longer followup is required to validate these conclusions.

\section{List of abbreviations used}

AUA: American Urological Association; CTC: Common Toxicity Criteria; CTV: clinical target volume; DVH: dose-volume histogram; EPIC: Expanded Prostate Cancer Index Composite; GI: gastrointestinal; GU: genitourinary; GTV: gross target volume; ISSAM: International Society for the Study of the Aging Male; NCl: National Cancer Institute; NPO: nothing by mouth; PTV: planning target volume; QoL: quality of life; SHIM: Sexual Health Inventory for Men; SF-12: Short Form-12; and SBRT: stereotactic body radiation therapy.

\section{Acknowledgements}

We acknowledge Robert Meier, M.D., Debra Freeman, M.D., Alan Katz, M.D. and Donald Fuller, M.D. for helpful discussions.

\section{Author details}

'Department of Radiation Medicine, Georgetown University Hospital, Washington, D.C., USA. ${ }^{2}$ Department of Urology, Georgetown University Hospital, Washington, D.C., USA. ${ }^{3}$ Department of Radiology, Georgetown University Hospital, Washington, D.C., USA. ${ }^{4}$ Department of Oncology, Lombardi Comprehensive Cancer Center, Georgetown University Medical Center, Washington, D.C., USA.

\section{Authors' contributions}

EO and SS participated in data collection, data analysis, manuscript drafting, table/figure creation and manuscript revision. $\mathrm{HH}, \mathrm{JK}, \mathrm{BE}, \mathrm{JR}, \mathrm{NP}, \mathrm{BS}, \mathrm{DB}$, and VC participated in data collection, data analysis and manuscript revision. SL, $\mathrm{XY}$ and $\mathrm{GZ}$ participated in treatment planning, data collection, data analysis, and manuscript revision. GB, NC, SD, GB, JP, KM and JL participated in treatment planning, data analysis and manuscript revision. $L A, R J, N D, B C$ and $\mathrm{AD}$ participated in the design and coordination of the study. SC drafted the manuscript, designed the study, and led the research effort. All authors have read and approved the final manuscript.

\section{Declaration of Competing interests}

BT Collins serves as a clinical consultant to Accuray Inc

The other authors declare that they have no competing interests.

Received: 26 December 2010 Accepted: 27 March 2011

Published: 27 March 2011

\section{References}

1. Fowler JF: The radiobiology of prostate cancer including new aspects of fractionated radiotherapy. Acta Oncol 2005, 44:265-276.

2. Kilby W, Dooley J, Kuduvalli G, Sayeh S, Maurer CRJ: The CyberKnife Robotic Radiosurgery System in 2010. Technol Cancer Res Treat 2010, 9:433-452
3. Webb S: Conformal intensity-modulated radiotherapy (IMRT) delivered by robotic linac-testing IMRT to the limit? Phys Med Biol 1999, 44:1639-1654

4. Hossain $S$, Xia P, Huang K, Descovich M, Chuang C, Gottschalk AR, Roach M, Ma L: Dose Gradient Near Target-Normal Structure Interface for Nonisocentric CyberKnife and Isocentric Intensity-Modulated Body Radiotherapy for Prostate Cancer. Int I Radiat Oncol Biol Phys.

5. Xie Y, Djajaputra D, King CR, Hossain S, Ma L, Xing L: Intrafractional motion of the prostate during hypofractionated radiotherapy. Int I Radiat Oncol Biol Phys 2008, 72:236-246.

6. Kaiser A, Schultheiss TE, Wong JY, Smith DD, Han C, Vora NL, Pezner RD, Chen YJ, Radany EH: Pitch, roll, and yaw variations in patient positioning. Int J Radiat Oncol Biol Phys 2006, 66:949-955.

7. King CR, Brooks JD, Gill H, Pawlicki T, Cotrutz C, Presti JC Jr: Stereotactic Body Radiotherapy for Localized Prostate Cancer: Interim Results of a Prospective Phase II Clinical Trial. Int J Radiat Oncol Biol Phys 2009, 73:1043-1048.

8. Friedland $J \mathrm{~L}$, Freeman DE, Masterson-McGary ME, Spellberg DM: Stereotactic body radiotherapy: an emerging treatment approach for localized prostate cancer. Technol Cancer Res Treat 2009, 8:387-392

9. Katz AJ, Santoro M, Ashley R, Diblasio F, Witten M: Stereotactic body radiotherapy for organ-confined prostate cancer. BMC Urol 2010, 10:1.

10. Ray ME, Thames HD, Levy LB, Horwitz EM, Kupelian PA, Martinez AA Michalski JM, Pisansky TM, Shipley WU, Zelefsky MJ, et al: PSA nadir predicts biochemical and distant failures after external beam radiotherapy for prostate cancer: a multi-institutional analysis. Int $J$ Radiat Oncol Biol Phys 2006, 64:1140-1150.

11. King CR, Lo A, Kapp DS: Testicular dose from prostate cyberknife: a cautionary note. Int J Radiat Oncol Biol Phys 2009, 73:636-637, author reply 637.

12. Shapiro E, Kinsella TJ, Makuch RW, Fraass BA, Glatstein E, Rosenberg SA, Sherins RJ: Effects of fractionated irradiation of endocrine aspects of testicular function. J Clin Oncol 1985, 3:1232-1239.

13. Petersen PM, Giwercman A, Daugaard G, Rorth M, Petersen JH, Skakkeaek NE, Hansen SW, von der Maase H: Effect of graded testicular doses of radiotherapy in patients treated for carcinoma-in-situ in the testis. J Clin Oncol 2002, 20:1537-1543.

14. Dixon SC, Knopf KB, Figg WD: The control of prostate-specific antigen expression and gene regulation by pharmacological agents. Pharmacol Rev 2001, 53:73-91.

15. Tinkler SD, Howard GC, Kerr GR: Sexual morbidity following radiotherapy for germ cell tumours of the testis. Radiother Oncol 1992, 25:207-212

16. Crawford ED, Barqawi AB, O'Donnell C, Morgentaler A: The association of time of day and serum testosterone concentration in a large screening population. BJU Int 2007, 100:509-513.

17. Wang C, Nieschlag E, Swerdloff R, Behre HM, Hellstrom WJ, Gooren LJ, Kaufman JM, Legros JJ, Lunenfeld B, Morales A, et al: Investigation, treatment and monitoring of late-onset hypogonadism in males: ISA, ISSAM, EAU, EAA and ASA recommendations. Eur J Endocrinol 2008, 159:507-514.

18. Oermann E, Hanscom H, Lei S, Suy S, Collins B, Batipps G, McGeagh K Jha R, Dawson N, Dritschilo A, et al: A Pilot Study of Intensity Modulated Radiation Therapy Plus a Hypofractionated Stereotactic Body Radiation Therapy Boost for the Treatment of Intermediate to High Risk Prostate Cancer. Technol Cancer Res Treat 2010, 9:453-462.

19. Barry MJ, Fowler FJ Jr, O'Leary MP, Bruskewitz RC, Holtgrewe HL, Mebust WK, Cockett AT: The American Urological Association symptom index for benign prostatic hyperplasia. The Measurement Committee of the American Urological Association. J Urol 1992, 148:1549-1557, discussion 1564.

20. Wei JT, Dunn RL, Litwin MS, Sandler HM, Sanda MG: Development and validation of the expanded prostate cancer index composite (EPIC) for comprehensive assessment of health-related quality of life in men with prostate cancer. Urology 2000, 56:899-905.

21. Rosen RC, Cappelleri JC, Gendrano N: The International Index of Erectile Function (IIEF): a state-of-the-science review. Int J Impot Res 2002, 14:226-244.

22. Zagars GK, Pollack A, von Eschenbach AC: Serum testosterone-a significant determinant of metastatic relapse for irradiated localized prostate cancer. Urology 1997, 49:327-334. 
23. D'Amico AV, Whittington R, Malkowicz SB, Schultz D, Blank K, Broderick GA, Tomaszewski JE, Renshaw AA, Kaplan I, Beard CJ, Wein A: Biochemical outcome after radical prostatectomy, external beam radiation therapy, or interstitial radiation therapy for clinically localized prostate cancer. Jama 1998, 280:969-974.

24. Alcantara P, Hanlon A, Buyyounouski MK, Horwitz EM, Pollack A: Prostatespecific antigen nadir within 12 months of prostate cancer radiotherapy predicts metastasis and death. Cancer 2007, 109:41-47.

25. Harman SM, Metter EJ, Tobin JD, Pearson J, Blackman MR: Longitudinal effects of aging on serum total and free testosterone levels in healthy men. Baltimore Longitudinal Study of Aging. J Clin Endocrinol Metab 2001, 86:724-731.

26. Wheeler MJ, Barnes SC: Measurement of testosterone in the diagnosis of hypogonadism in the ageing male. Clin Endocrinol (Oxf) 2008, 69:515-525.

27. Sanda MG, Dunn RL, Michalski J, Sandler HM, Northouse L, Hembroff $L$, Lin X, Greenfield TK, Litwin MS, Saigal CS, et al: Quality of life and satisfaction with outcome among prostate-cancer survivors. N Engl J Med 2008, 358:1250-1261.

28. Joos H, Sedlmayer F, Gomahr A, Rahim HB, Frick J, Kogelnik HD, Rettenbacher $L$ : Endocrine profiles after radiotherapy in stage I seminoma: impact of two different radiation treatment modalities. Radiother Oncol 1997, 43:159-162.

29. Bruheim K, Svartberg J, Carlsen E, Dueland S, Haug E, Skovlund E, Tveit KM, Guren MG: Radiotherapy for rectal cancer is associated with reduced serum testosterone and increased FSH and LH. Int I Radiat Oncol Biol Phys 2008, 70:722-727.

30. Pickles T, Graham P: What happens to testosterone after prostate radiation monotherapy and does it matter? J Urol 2002, 167:2448-2452.

31. Tomic R, Bergman B, Damber JE, Littbrand B, Lofroth PO: Effects of external radiation therapy for cancer of the prostate on the serum concentrations of testosterone, follicle-stimulating hormone, luteinizing hormone and prolactin. J Urol 1983, 130:287-289.

32. Yau I, Vuong T, Garant A, Ducruet T, Doran P, Faria S, Liberman S, Richard C, Letellier F, Charlebois $P$, et al: Risk of hypogonadism from scatter radiation during pelvic radiation in male patients with rectal cancer. Int $J$ Radiat Oncol Biol Phys 2009, 74:1481-1486.

33. Yoon FH, Perera F, Fisher B, Stitt L: Alterations in hormone levels after adjuvant chemoradiation in male rectal cancer patients. Int $J$ Radiat Oncol Biol Phys 2009, 74:1186-1190.

34. Hall EJ: Intensity-modulated radiation therapy, protons, and the risk of second cancers. Int J Radiat Oncol Biol Phys 2006, 65:1-7.

35. King $C R$, Maxim PG, Hsu A, Kapp DS: Incidental testicular irradiation from prostate IMRT: it all adds up. Int I Radiat Oncol Biol Phys 2010, 77:484-489.

36. Fuller DB: Testicular dose from prostate cyberknife: a cautionary note in regard to King et al. Int J Radiat Oncol Biol Phys 2009, 73:637.

37. Cooper CS, Maclndoe JH, Perry PJ, Yates WR, Williams RD: The effect of exogenous testosterone on total and free prostate specific antigen levels in healthy young men. J Urol 1996, 156:438-441, discussion 441-432.

38. Monath JR, McCullough DL, Hart LJ, Jarow JP: Physiologic variations of serum testosterone within the normal range do not affect serum prostate-specific antigen. Urology 1995, 46:58-61.

39. Guay A, Seftel AD, Traish A: Hypogonadism in men with erectile dysfunction may be related to a host of chronic illnesses. Int J Impot Res 2010, 22:9-19.

40. Lips IM, Dehnad H, van Gils CH, Boeken Kruger AE, van der Heide UA, van Vulpen M: High-dose intensity-modulated radiotherapy for prostate cancer using daily fiducial marker-based position verification: acute and late toxicity in 331 patients. Radiat Oncol 2008, 3:15.

41. Ghadjar P, Vock J, Vetterli D, Manser P, Bigler R, Tille J, Madlung A, Behrensmeier F, Mini R, Aebersold DM: Acute and late toxicity in prostate cancer patients treated by dose escalated intensity modulated radiation therapy and organ tracking. Radiat Oncol 2008, 3:35.

42. Pickles T, Duncan G, Graham P: Re: Hermann et al., low testosterone levels and quality of life. Radiother Oncol 2006, 78:107-108.

doi:10.1186/1756-8722-4-12

Cite this article as: Oermann et al:: Low incidence of new biochemical and clinical hypogonadism following hypofractionated stereotactic body radiation therapy (SBRT) monotherapy for low- to intermediaterisk prostate cancer. Journal of Hematology \& Oncology 2011 4:12.

\section{Submit your next manuscript to BioMed Central and take full advantage of:}

- Convenient online submission

- Thorough peer review

- No space constraints or color figure charges

- Immediate publication on acceptance

- Inclusion in PubMed, CAS, Scopus and Google Scholar

- Research which is freely available for redistribution

Submit your manuscript at www.biomedcentral.com/submit 